\title{
UČESTALOST KOMORBIDNIH BOLESTI U OBOLJELIH OD KOLOREKTALNOG ADENOKARCINOMA
}

\author{
Pejana Rastovićn ${ }^{1,2}$, Snježana Šekerija ${ }^{1}$, Marko Kordić ${ }^{1}$, Anđela Azinović ${ }^{1}$, Zdrinko Brekalo ${ }^{1,2}$ \\ ${ }^{1}$ Klinika za kirurgiju, Sveučilišna klinička bolnica Mostar, 88000 Mostar, Bosna i Hercegovina \\ ${ }^{2}$ Medicinski fakultet, Sveučilište u Mostaru, 88000 Mostar, Bosna i Hercegovina \\ Rad je primljen 18.3.2016. Rad je korigiran 10.4.2016. Rad je prihvaćen 18.4.2016.
}

\section{SAŽETAK}

UVOD: Kolorektalni adenokarcinom jedan je od vodećih uzroka morbiditeta i mortaliteta širom svijeta. Najčešće se javlja u osoba starije životne dobi za koje je poznato da imaju i opći porast morbiditeta često u vidu kroničnih bolesti udruženih u definirane skupine. Komorbidne bolesti u oboljelih od kolorektalnog adenokarcinoma značajno utječu na tijek i ishod liječenja.

CILJ: Utvrditi učestalost najčešćih komorbidnih bolesti u bolesnika s kolorektalnim adenokarcinomom hospitaliziranih u SKB Mostar i usporediti ih s učestalošću tih bolesti u općoj populaciji. Drugi cilj je bio utvrditi postoji li povezanost komorbidnih bolesti sa sijelom kolorektalog adenokarcinoma.

METODE: U ovoj retrospektivnoj studiji ispitivanu skupinu činilo je 74 bolesnika s kolorektalnim adenokarcinomom koji su operirani na Klinici za kirurgiju SKB Mostar, dok se kontrolna skupina sastojala od 100 ispitanika iz opće populacije. Ulazni podaci uzimani su iz povijesti bolesti, odnosno medicinskih kartona. Komorbiditetima su smatrani nozološki entiteti prisutni i registrirani u trenutku pregleda pred operativni zahvat.

REZULTATI: Najčešće komorbidne bolesti u ispitivanoj skupini bili su dijabetes melitus, arterijska hipertenzija i anemije. Oboljeli od kolorektalnog adenokarcinoma su statistički značajno učestalije imali dijabetes melitus ( $\mathrm{p}=0,000)$, arterijsku hipertenziju $(\mathrm{p}=0,010)$ i mikrocitnu anemiju $(\mathrm{p}=0,01)$ u odnosu na kontrolnu skupinu. Oboljeli od kolorektalnog adenokarcinoma imali su statistički značajno niže prosječne koncentracije hemoglobina u usporedbi s kontrolnim ispitanicima $(\mathrm{p}=0,045)$. Nije nađeno statistički značajnih razlika u učestalosti komorbiditeta s obzirom na sijelo kolorektalnog adenokarcinoma.

ZAKLJUČAK: Oboljeli od kolorektalnog adenokarcinoma statistički značajno učestalije imaju diabetes mellitus, arterijsku hipertenziju i mikrocitnu anemiju. Nije nađeno statistički značajnih razlika u učestalosti ovih komorbiditeta s obzirom na sijelo kolorektalnog adenokarcinoma.

Ključne riječi: kolorektalni karcinom, komorbiditeti, dijabetes melitus, povišeni krvni tlak, anemija

Osoba za razmjenu informacija:

Pejana Rastović, dr. med.

e-mail: pejana_rastovic@yahoo.com

\section{UVOD}

Poznato je da kolorektalni adenokarcinom predstavlja jedan od glavnih uzroka morbiditeta i mortaliteta širom svijeta (1). Zbog dobro provođenih skrining programa, kolorektalni adenokarcinom je treća najčešće dijagnosticirana maligna bolest u svijetu, a prema nekim studijama druga u Europi $(2,3)$.
Kolorektalni adenokarcinom je u suštini heterogena skupina bolesti, kako zbog histopatološkog izgleda, tako i zbog svojih karakteristika na molekularnoj i genetskoj razini $(4,5)$. Najčešće nastaje iz određenih podvrsta polipa debelog crijeva u procesu koji se postupno odvija, kroz seriju mutacija 
kojima doprinose okolišni čimbenici (4). U Sjedinjenim Američkim Državama (SAD) provedeno je veliko istraživanje na 17275 kolonoskopiranih bolesnika, odnosno 7756 polipektomiranih, koje je pokazalo da je nalaz kolorektalnog polipa sve češći s porastom životne dobi, s vrhom incidencije sa 70 i više godina (5). Premaligne lezije debelog crijeva kao i rani stadiji adenokarcinoma uglavnom su asimptomatski, za razliku od uznapredovalog i često neizlječivog adenokarcinoma (4). Prema jednoj meta analizi provedenoj također u SAD-u, nađeno je da nalaz kolorektalnog adenokarcinoma ima $1,7 \%$ kolonoskopiranih 59-ogodišnjaka (6). Stoga se smatra da su opravdani kolonoskopski skrining testovi često asimptomatskih osoba preko 50 godina starosti (4). Zapadnjački način života i prehrane direktno je epidemiološki povezan s kolorektalnim adenokarcinomom, što je najilustrativnije u nekim nerazvijenim zemljama u kojima se zapaža povećena incidencija kolorektalnog adenokarcinoma sukladno prihvatanju ovakvog stila života (7).

U starijim dobnim skupinama također se uočava opći porast morbiditeta, često u vidu kroničnih bolesti udruženih u definirane skupine, uključujući i neoplazme svih lokalizacija $(8,9)$. Godine 2004. i 2005. australski javnozdravstveni nadzor prijavio je da gotovo svi Australci u dobi iznad 65 godina imaju najmanje jednu kroničnu bolest, a $80 \%$ njih ima tri ili više kroničnih stanja (10). Slične rezultate pokazala su istraživanja provedena i u zemljama Zapada (11). U jednoj danskoj kohortnoj studiji nađeno je da stariji bolesnici s kolorektalnim adenokarcinomom imaju veću prevalenciju komorbiditeta nego kontrolni ispitanici iz opće populacije, koji su im bili kompatibilni po dobi i spolu (12). Prema rezultatima istraživanja provedenog u SAD-u bolesnici s kolorektalnim adenokarcinomom, koji imaju tri i više komorbiditeta, imaju 40-50 \% veći rizik od smrti u jednoj godini (13). Liječenje kolorektalnih neoplazmi u starijih bolesnika u mnogome je zahtjevnije, a ponajviše upravo zbog prisutnih komorbiditeta $\mathrm{i}$ smanjene biološke rezerve organa. Dob i teškoće vezane za prisutne komorbiditete utječu na preživljenje ovih bolesnika, osobito nakon kemoterapijskog liječenja (14).

\section{CILJ}

Utvrditi učestalost najčešćih komorbidnih bolesti u bolesnika s kolorektalnim adenokarcinomom hospitaliziranih u SKB Mostar i usporediti ih s učestalošću tih bolesti u općoj populaciji. Drugi cilj je bio utvrditi postoji li povezanost komorbidnih bolesti sa sijelom kolorektalog adenokarcinoma.

\section{METODE}

Provedeno je retrospektivno istraživanje u koje je ukupno uključeno 174 ispitanika. Ispitivanu skupinu činilo je 74 bolesnika koji su hospitalizirani zbog kolorektalnog adenokarcinoma na Klinici za kirurgiju Sveučilišne kliničke bolnice (SKB) Mostar, u periodu od 1. siječnja 2013. do 31. prosinca 2015. godine. Kontrolnu skupinu sačinjavalo je 100 ispitanika iz opće populacije koji su regrutirani prilikom sistematskih pregleda iz različitih razloga (vozačke dozvole, zaposlenje, upis na fakultet itd.) u ambulantama obiteljske medicine Doma zdravlja Mostar. U ispitivanu skupinu uključeni su bolesnici s dokazanim kolorektalnim adenokarcinomom, koji su gastroenterološki i anesteziološki obrađeni u bolničkim ili ambulantnim uvjetima, nakon čega su operirani na Klinici za kirurgiju SKB Mostar. Podaci o vrsti komorbiditeta za oboljele od kolorektalnog adenoarcinoma uzimani su iz potpunih povijesti bolesti, kao i iz anesteziološkog i internističkog nalaza. Podaci o zdravstvenom stanju i prisutnim bolestima u ispitanika iz kontrolne skupine uzimani su iz medicinskih kartona/nalaza. Komorbiditetima su smatrani nozološki entiteti prisutni i registrirani u trenutku pregleda pred operativni zahvat. Tijekom statističke obrade podataka u obzir su uzeta tri najučestalija komorbiditeta (anemija, dijabetes, arterijska hipertenzija) dok su ostala komorbidna stanja zbog vrlo niske učestalosti i relativno malog uzorka ispitanika izostavljena. Iz studije su bili isključeni ispitanici čija medicinska dokumentacija nije bila potpuna.

\section{ANALIZA I STATISTIČKA OBRADA PODATAKA}

Nominalne i ordinalne varijable analizirane su $\mathrm{Hi}$ kvadrat testom. Za kontinuirane varijable prvo se 
analizirala simetričnost njihove raspodjele s pomoću Kolmogorov-Smirnovljeva testa a potom zbog dokazane simetričnosti raspodjele koristila se aritmetička sredina i standardna devijacija za prikaz srednje vrijednosti i mjera raspršenja, a za usporedbu tih varijabli koristili su se parametrijski testovi (Studentov t-test, ANOVA s Tukey i Scheffe post hoc testom). Razine značajnosti od $\mathrm{p}<0,05$ bile su uzete kao statistički značajne. Za statističku analizu dobivenih podataka rabio se programski sustav SPSS for Windows (inačica 21.0, SPSS Inc, Chicago, Illinois, SAD) i Microsoft Excell (inačica 11 Microsoft Corporation, Redmond, WA, SAD).

\section{REZULTATI}

$\mathrm{U}$ ispitivanoj skupini bolesnici muškog spola bili su statistički značajnije zastupljeni u odnosu na kontrolnu skupinu $(\mathrm{p}=0,036)$ (Slika 1$)$.

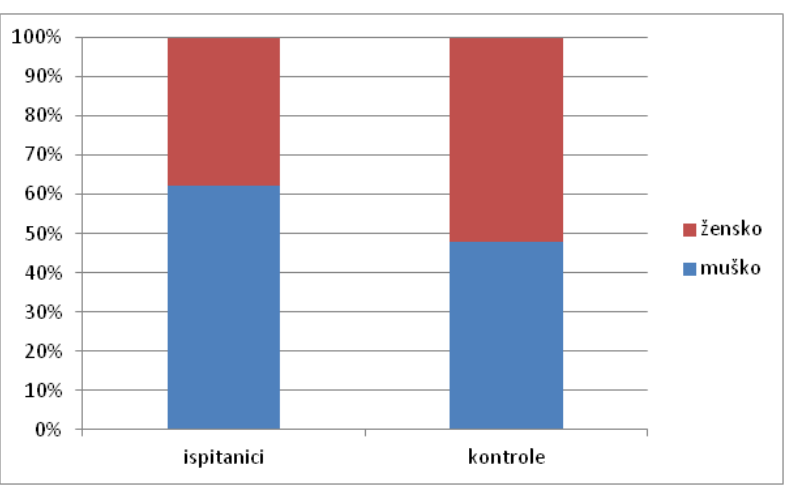

Slika 1. Spolna razdioba ispitanika

Prosječna životna dob u ispitivanoj skupini bila je $66,9 \pm 11,3$ godina a u kontrolnoj $48,0 \pm 12,0$ godina što se pokazalo statistički značajnim $(\mathrm{p}<0,001)$.

U statističkoj obradi podataka godine ispitanika pretvorene su iz kontinuirane u ordinarnu varijablu prema dobnim skupinama (skupina 1 ispitanici do 30 godina života, skupina 2 od 31 do 45 , skupina 3 od 46 do 60 i skupina 4 od 61 godine naviše) (Tablica 1).
Tablica 1. Učestalost ispitanika prema dobnoj skupini u ispitivanoj i kontrolnoj skupini

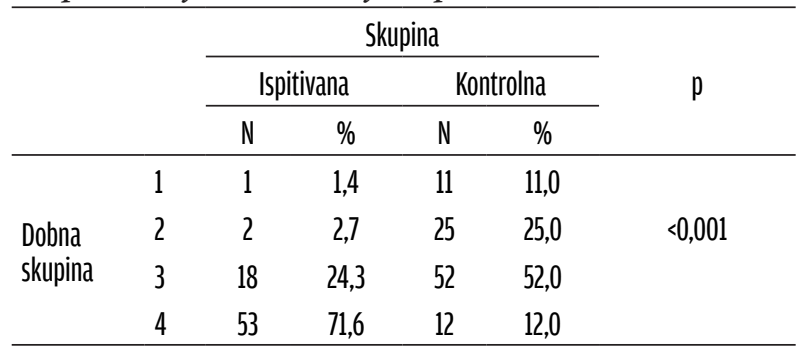

Ispitanici starije životne dobi (>61 godine) bili su statistički značajno zastupljeniji u ispitivanoj u odnosu na kontrolnu skupinu ( $\mathrm{p}<0,001)$.

Od svih nozoloških entiteta, najčešća komorbidna stanja bila su diabetes mellitus (DM), arterijska hipertenzija (HTA) i anemije.

$\mathrm{U}$ ispitivanoj skupini $16,2 \%(\mathrm{n}=12)$ imalo je verificiran DM dok je u kontrolnoj skupini 7,0 \% $(n=7)$ imalo DM što se pokazalo statistički značajnim $(\mathrm{p}<0,001)$. Oboljeli od kolorektalnog adenokarcinoma imali su statistički značajno veću prosječnu koncentraciju glukoze u krvi (GUK) $(7,4 \pm 4,5 \mathrm{mmol} / \mathrm{L})$ $\mathrm{u}$ odnosu na kontrolnu skupinu $(5,5 \pm 1,4 \mathrm{mmol} / \mathrm{L})$ $(\mathrm{p}=0,001)$.

Kod ispitanika koji su imali verificiran DM vrijednosti GUK-a nisu se razlikovale bez obzira na skupinu, dok su se kod ispitanika bez verificiranog DM vrijednosti GUK-a razlikovale i bile statistički značajno veće $\mathrm{u}$ ispitivanoj skupini $(\mathrm{p}=0,005)$ (Tablica 2).

Tablica 2. Prosječne vrijednosti GUK-a u mmol/L u ispitivanoj i kontrolnoj skupini sobzirom na verificirani $D M$

\begin{tabular}{|c|c|c|c|c|c|}
\hline & & Skupina & $\begin{array}{c}\text { Prosječna } \\
\text { koncentracija }\end{array}$ & $\begin{array}{c}\text { Standardna } \\
\text { devijacija }\end{array}$ & $p$ \\
\hline Ima & Vrijednosti & Ispitanici & 9,1 & 3,45 & 0,994 \\
\hline DM & GllK-d & Kontrole & 9,1 & 2,74 & \\
\hline Nema & Vrijednosti & Ispitanici & 7,1 & 4,72 & 0,005 \\
\hline DM & GUKK-d & Kontrole & 5,2 & 0,72 & \\
\hline
\end{tabular}

U ispitivanoj skupini 51,4 \% ispitanika imalo je verificiranu arterijsku hipertenziju a u kontrolnoj skupini 33,0\%, što se također pokazalo statistički značajnim $(p=0,01)$. Iako je ispitivana skupina češće imala arterijsku hipertenziju, prosječne vrijednosti sistoličkog i dijastoličkog krvnog tlaka nisu se značajno razlikovale između ispitivane i kontrolne skupine (Tablica 3). 
Tablica 3. Prosječne vrijednosti sistoličkog i dijastoličkog krvnog tlaka u mm Hg u ispitivanoj i kontrolnoj skupini

\begin{tabular}{lcccc}
\hline & Skupina & $\begin{array}{c}\text { Prosječna } \\
\text { vrijednost }\end{array}$ & $\begin{array}{c}\text { Standardna } \\
\text { devijacija }\end{array}$ & p \\
\hline Vrijednosti sistoličkog & Ispitanici & 133,2 & 24,8 & 0,743 \\
krvnog tlaka & Kontrole & 134,3 & 17,9 & \\
Vrijednosti dijastoličkog & Ispitanici & 81,0 & 9,5 & 0,379 \\
krvnog tlaka & Kontrole & 82,5 & 11,4 & \\
\hline
\end{tabular}

Ispitanici iz kontrolne skupine značajno učestalije su bili bez anemije u odnosu na oboljele od kolorektalnog adenokarcinoma, dok su oboljeli od kolorektalnog adenokarcinoma statistički značajno učestalije imali mikrocitnu anemiju u odnosu na kontrolne ispitanike $(\mathrm{p}=0,01)$ (Tablica 4$)$.

Tablica 4. Učestalost anemija $u$ ispitivanoj $i$ kontrolnoj skupini

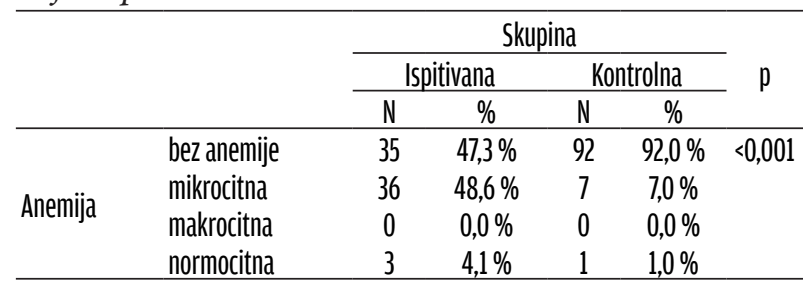

Prosječne koncentracije hemoglobina kao mjera anemije očekivano su u oboljelih od kolorektalnog adenokarcinoma bile statistički značajno niže $(119,4 \pm 20,2 \mathrm{mmol} / \mathrm{L}) \mathrm{u}$ usporedbi s kontrolnim ispitanicima $(149 \pm 15,9 \mathrm{mmol} / \mathrm{L})(\mathrm{p}=0,045)$. Uspoređujući vrijednosti hemoglobina između ispitivane i kontrolne skupine u odnosu na postojanje i vrstu anemije, nađeno je da su u svakoj uspoređivanoj podskupini oboljeli od kolorektalnog adenokarcinoma imali statistički niže vrijednosti hemoglobina (Tablica 5).

Tablica 5. Usporedba prosječnih vrijednosti hemoglobina u mmol/L izmedu ispitivane i kontrolne skupine u odnosu na postojanje i vrstu anemije

\begin{tabular}{llllccc}
\hline \multicolumn{2}{c}{ Vrsta anemije } & Skupina & Broj & $\begin{array}{c}\text { Prosječne vijjednosti } \\
\text { hemoglobina }\end{array}$ & $\begin{array}{c}\text { Standardna } \\
\text { devijacija }\end{array}$ & p \\
\hline \multirow{2}{*}{ Bez anemije } & Hb po & ispitanici & 35 & 135,7 & 13,24 & $<0,001$ \\
& prijemu & kontrole & 92 & 151,6 & 14,24 & \\
\hline \multirow{2}{*}{ Mikrocitna } & Hb po & ispitanici & 34 & 103,9 & 12,47 & 0,001 \\
& prijemu & kontrole & 7 & 122,3 & 11,25 & \\
\hline \multirow{2}{*}{ Normocitna } & Hb po ispitanici & 3 & 107,0 & 4,36 & 0,033 \\
& prijemu & kontrole & 1 & 134,0 & & \\
\hline
\end{tabular}

Sijelo kolorektalnog adenokarcinoma bilo je u $18,9 \%(n=14)$ slučajeva u području cekuma i ascendentnog kolona, u 8,1 \% $(n=6)$ slučajeva u području hepatalne i lijenalne fleksure te transverzalnog kolona, $6,8 \%(n=5)$ slučajeva u području descendentnog kolona, 35,1 \% $(n=25)$ u području sigmoidnog kolona i $31,1 \%(n=23)$ u području rektuma. Ako podjelimo debelo crijevo na desno i lijevo (uobičajena kirurška podjela s obzirom na vaskularizaciju), statistički učestalije je kolorektalni adenoarcinom bio lokaliziran u području lijevog kolona $(n=54) \mathrm{u}$ odnosu na desni $(n=20)(p<0,001)$.

Tablica 6. Učestalost DM u odnosu na sijelo kolorektalnog adenokarcinoma

\begin{tabular}{|c|c|c|c|c|c|}
\hline \multirow{3}{*}{ Sijelo adenokarcinoma } & \multicolumn{4}{|c|}{ DM } & \multirow{3}{*}{$p$} \\
\hline & \multicolumn{2}{|c|}{ ima DM } & \multicolumn{2}{|c|}{ nema DM } & \\
\hline & $\mathrm{N}$ & $\%$ & $\mathrm{~N}$ & $\%$ & \\
\hline Cekum i ascendens & 3 & $25,0 \%$ & 11 & $18,0 \%$ & 0,108 \\
\hline Fleksure i transversum & 0 & $0,0 \%$ & 6 & $9,8 \%$ & \\
\hline Colon descendens & 1 & $8,3 \%$ & 4 & $6,6 \%$ & \\
\hline Sigma & 1 & $8,3 \%$ & 24 & $39,3 \%$ & \\
\hline Rectum & 7 & $58,3 \%$ & 16 & $26,2 \%$ & \\
\hline
\end{tabular}

U oboljelih od kolorektalnog adenokarcinoma nije bilo statistički značajne razlike u učestalosti dijagnoze DM s obzirom na sijelo neoplazme $(\mathrm{p}=0,108)$ (Tablica 6).

Tablica 7. Prosječne vrijednosti koncentracije GUK-a u mmol/L u odnosu na sijelo kolorektalnog adenokarcinoma

\begin{tabular}{lcccc}
\hline Sijelo adenokarcinoma & $\begin{array}{c}\text { Prosječne } \\
\text { koncentracije GUK-a }\end{array}$ & N & $\begin{array}{c}\text { Standardna } \\
\text { devijacija }\end{array}$ & p \\
\hline Cekum i ascendens & 7,3 & 13 & 2,68 & \\
Fleksure i transversum & 5,9 & 6 & 1,03 & 0,512 \\
Colon descendens & 6,5 & 4 & 1,25 & \\
Sigma & 6,7 & 24 & 1,67 & \\
Rectum & 8,8 & 22 & 7,48 & \\
\hline
\end{tabular}

Prosječne koncentracije GUK-a u oboljelih od kolorektalnog adenokarcinoma nisu se statistički značajno razlikovale s obzirom na sijelo neoplazme $(\mathrm{p}=0,512)$ (Tablica 7$)$. 
Tablica 8. Učestalost HTA u odnosu na sijelo kolorektalnog adenokarcinoma

\begin{tabular}{|c|c|c|c|c|c|}
\hline \multirow{3}{*}{ Sijelo adenokarcinoma } & \multicolumn{4}{|c|}{ HTA } & \multirow{3}{*}{$p$} \\
\hline & \multicolumn{2}{|c|}{ Ima } & \multicolumn{2}{|c|}{ Nema } & \\
\hline & $\mathrm{N}$ & $\%$ & $\mathrm{~N}$ & $\%$ & \\
\hline Cekum i ascendens & 7 & 18,4 & 6 & 17,6 & 0,111 \\
\hline Fleksure i transversum & 4 & 10,5 & 2 & 5,9 & \\
\hline Colon descendens & 3 & 7,9 & 2 & 5,9 & \\
\hline Sigma & 8 & 21,1 & 17 & 50,0 & \\
\hline Rectum & 16 & 42,1 & 7 & 20,6 & \\
\hline
\end{tabular}

U oboljelih od kolorektalnog adenokarcinoma nije bilo statistički značajne razlike u učestalosti dijagnoze HTA s obzirom na sijelo neoplazme $(\mathrm{p}=0,111)$ (Tablica 8$)$.

Tablica 9. Prosječne vrijednosti sistoličkog krvnog tlaka u odnosu na sijelo kolorektalnog adenokarcinoma

\begin{tabular}{lcccc}
\hline Sijelo adenokarcinoma & $\begin{array}{c}\text { Prosječne vijednosti } \\
\text { sistoličkog krvnog tlaka }\end{array}$ & N & $\begin{array}{c}\text { Standardna } \\
\text { devijacija }\end{array}$ & p \\
\hline Cekum i ascendens & 132,5 & 14 & 20,17 & \\
Fleksure i transversum & 126,7 & 6 & 23,38 & 0,512 \\
Colon descendens & 135,0 & 5 & 11,18 & \\
Sigma & 126,3 & 24 & 32,87 & \\
Rectum & 142,5 & 22 & 17,37 & \\
\hline
\end{tabular}

Prosječne vrijednosti sistoličkog krvnog tlaka u oboljelih od kolorektalnog adenokarcinoma nisu se statistički značajno razlikovale s obzirom na sijelo neoplazme $(\mathrm{p}=0,512)$ (Tablica 9).

Tablica 10. Prosječne vrijednosti dijastoličkog krvnog tlaka u odnosu na sijelo kolorektalnog adenokarcino-

\begin{tabular}{lcccc}
$m a$ & & & & \\
\hline $\begin{array}{l}\text { Sijelo } \\
\text { adenokarcinoma }\end{array}$ & $\begin{array}{c}\text { Prosječne vrijednosti } \\
\text { dijastoličkog krvnog tlaka }\end{array}$ & $\mathrm{N}$ & $\begin{array}{c}\text { Standardna } \\
\text { devijacija }\end{array}$ & $\mathrm{p}$ \\
\hline Cekum i ascendens & 79,6 & 14 & 9,03 & \\
Fleksure i & 76,7 & 6 & 10,32 & 0,587 \\
transversum & 78,0 & 5 & 9,08 & \\
Colon descendens & 82,4 & 23 & 9,27 & \\
Sigma & 82,3 & 22 & 10,20 & \\
Rectum & & &
\end{tabular}

Prosječne vrijednosti dijastoličkog krvnog tlaka u oboljelih od kolorektalnog adenokarcinoma nisu se statistički značajno razlikovale s obzirom na sijelo neoplazme $(\mathrm{p}=0,578)$ (Tablica 10).

Nije nađena ni statistički značajna razlika u učestalosti anemija s obzirom na lokalizaciju (sijelo) kolorektalnog adenokarcinoma $(\mathrm{p}=0,051)$, ali je nakon podjele lokalizacije na desni i lijevi kolon nađeno da bolesnici s adenokarcinomom lokaliziranim na desnom kolonu imaju statistički značajno učestaliju mikrocitnu anemiju $(\mathrm{p}=0,002)$.

Tablica 11. Prosječne vrijednosti hemoglobina u odnosu na sijelo kolorektalnog adenokarcinoma

\begin{tabular}{lcccc}
\hline Sijelo adenokarcinoma & $\begin{array}{c}\text { Prosječne vrijednosti } \\
\text { hemoglobina }\end{array}$ & N & $\begin{array}{c}\text { Standardna } \\
\text { devijacija }\end{array}$ & p \\
\hline Cekum i ascendens & 107,3 & 13 & 17,92 & \\
Fleksure i transversum & 105,7 & 6 & 9,87 & 0,032 \\
Colon descendens & 116,0 & 5 & 9,75 & \\
Sigma & 122,9 & 25 & 20,14 & \\
Rectum & 127,0 & 23 & 21,18 & \\
\hline
\end{tabular}

Oboljeli od kolorektalnog adenokarcinoma lokaliziranog u području cekuma i ascendentnog kolona imaju najniže prosječne vrijednosti hemoglobina, osobito značajno u usporedbi s prosječnim vrijednostima hemoglobina kod bolesnika s lokalizacijom neoplazme u području rektuma $(\mathrm{p}=0,032)$ (Tablica 11). Ako i u ovom slučaju podijelimo debelo crijevo na desno i lijevo, bolesnici s kolorektalnim adenokarcinomom u području desnog imali su prosječne vrijednosti hemoglobina 106,8 $\mathrm{mmol} / \mathrm{L}$ a lijevog $124,0 \mathrm{mmol} / \mathrm{L}$ što se pokazalo statistički značajnim $(\mathrm{p}=0,001)$.

\section{RASPRAVA}

Kolorektalni adenokarcinom druga je maligna bolest po učestalosti kod oba spola, iza karcinoma pluća za muškarce i karcinoma dojke za žene, dok neke studije navode veću učestalost kolorektalnog adenokarcinoma kod muškaraca što je potvrdilo i naše istraživanje (15).

Prosječna životna dob oboljelih od kolorektalnog adenokarcinoma u našem istraživanju bila je značajno veća od kontrolne skupine. Ovi rezultati su slični rezultatima drugih istraživanja, što se posredno može dovesti u vezu s najvećom incidencijom kolorektalnog karcinoma vezanom za veću dob u općoj populaciji. Pored toga, $u$ ispitivanoj skupini najviše je ispitanika starijih od 61 godinu, dok je u kontrolnom uzorku najviše onih od 46 do 60 godina, što nam opet sugerira da veću pojavnost kolorektalnog 
karcinoma možemo očekivati u starijim dobnim skupinama $(16,17)$.

Nalaz anemije, osobito mikrocitne, nije iznenađujući komorbiditet u bolesnika s kolorektalnim adenokarcinomom što govore i naši podaci prema kojima je anemija, a osobito mikrocitna bila statistički značajno učestalija u oboljelih od kolorektalnog karcinoma. Pored toga, vrijednosti hemoglobina u oboljelih od kolorektalnog adenokarcinoma bile su prosječno $119 \mathrm{mmol} / \mathrm{L}$, što se smatra subnormalnim za oba spola, u odnosu na vrijednosti hemoglobina od $149 \mathrm{mmol} / \mathrm{L}$ u kontrolnih ispitanika. Često je upravo anemija prvi znak kolorektalne neoplazme i zbog nje bolesnici provode opsežnu gastroeneterološku obradu. Snižene vrijednosti hemoglobina kod muškaraca i žena u menopauzi, uz odsutnost podataka o gubitku krvi koja eventualno može opravdati navedene vrijednosti, treba pobuditi sumnju na neoplazmu, najčešće upravo kolorektalnu (18-20). Mikrocitna anemija simptomatičnija je za desni kolon što je pokazalo i naše istraživanje, premda klasična anatomska podjela debelog crijeva na dijelove i testiranje na prisustvo anemija nije uspjelo dokazati simptomatičnost iste, vjerojatno zbog malog uzorka (19). Smatra se da neoplazme desnog kolona mogu dugo asimptomatski rasti i kronično krvariti, a neke studije sugeriraju da je u pitanju posebna mutacija kod desnostranih neoplazmi koja utiče na metabolizam željeza (21). Kada je u pitanju lijevi kolon, valja primijetiti da su i tu prosječne vrijednosti hemoglobina često snižene ili subnormalne. Pregled stolice na okultno krvarenje i dalje ima svoje mjesto u skriningu kolorektalnih neoplazmi, kao i rektosigmoidoskopija (20).

Verificirana hipertenzija kod bolesnika s kolorektalnom neoplazmom povezuje se kako sa zajedničkim rizičnim faktorima nastajanja, tako i kao još nedovoljno razjašnjeni čimbenik u etiopatogenezi ove bolesti $(17,22)$. Promjena prehrane i uvođenje namirnica koje snižavaju krvni tlak, također značajno smanjuju i pojavnost kolorektalnog adenokarcinoma (22). Prevalencija hipertenzije kod bolesnika s kolorektalnim adenokarcinomom različita je diljem svijeta, a naši rezultati prilično su visoki. Jednako vrijedi i za diabetes mellitus. Istraživanje provedeno u Iranu, na 1127 bolesnika s kolorektalnim karcinomom, izvještava da 13,38 \% ispitanika ima diabetes mellitus tipa 2 a njih 8,69 \% verificiranu arterijsku hipertenziju (23). Povezanost prosječnih vrijednosti krvnog tlaka i koncentracije GUK-a odnosu na sijelo kolorektalnog adenokarcinoma u ovom istraživanju nije nađena, što su pokazale i slične studije rađene na velikim uzorcima ispitanika $(24,25)$. Studija provedena u Tajvanu, na 1197 ispitanika, također nije našla povezanost između sijela kolorektanog adenokarcinoma i prisustva dijabetesa i hipertenzije (25). Vrijednost sistoličkog krvnog tlaka kod bolesnika koji imaju verificiranu hipertenziju nije bila statistički značajnije povišena u odnosu na bolesnike koji nemaju verificiranu hipertenziju, a isto vrijedi i za dijastolički tlak. Ovakav rezultat tumačimo dobrom medikamentoznom kontrolom hipertenzije, uz opasku da sama vrsta i doza antihipertenziva nisu bili predmet ovog istraživanja (26).

Pored toga, vrijednosti GUK-a u obje ispitivane skupine s obzirom na dijagnozu dijabetesa nisu se značajno razlikovale što se može protumačiti na isti način, dobrom preoperativnom pripremom i medikamentoznom kontrolom. Zanimljivo je da su vrijednosti GUK-a kod bolesnika s kolorektalnim adenokarcinomom i to bez verificiranog dijabetesa značajno više nego kod kontrolnih ispitanika bez dijabetesa, i da su te vrijednosti klinički na granici za uspostavljanje dijagnoze dijabetesa. Sukladno ovim rezultatima napomenut ćemo da više dosadašnjih istraživanja dovodi u vezu dijabetes i kolorektalni karcinom $(17,22,23)$. Iako za povezanost hipertenzije i kolorektalnog adenokarcinoma nema konkretnog dokaza o nekom patofiziološkom putu u indukciji karcinogeneze, povezanost dijabetesa i hipertenzije u općoj populaciji dobro je poznata (27).

\section{ZAKLJUČAK}

Oboljeli od kolorektalnog adenokarcinoma statistički značajno učestalije imaju diabetes mellitus, arterijsku hipertenziju i mikrocitnu anemiju. Nije nađeno statistički značajnih razlika u učestalosti ovih komorbiditeta s obzirom na sijelo kolorektalnog adenokarcinoma. 


\section{LITERATURA}

1. Faivre J, Lemmens VE, Quipourt V, Bouvier AM. Management and survival of colorectal cancer in the elderly in population-based studies. Eur J Cancer. 2007;43:2279-84.

2. Tsilidis KK, Kasimis JC, Lopez DS, Ntzani EE, Ioannidis JP. Type 2 diabetes and cancer: umbrella review of meta-analyses of observational studies. BMJ. 2015;350:7607.

3. Ferlay J, Shin HR, Bray F, Forman D, Mathers C, Parkin DM. Estimates of worldwide burden of cancer in 2008: GLOBOCAN 2008. Int J Cancer. 2010;127:2893-917.

4. Cappell MS. From colonic polyps to colon cancer: pathophysiology, clinical presentation, screening and colonoscopic therapy. Minerva Gastroenterol Dietol. 2007;53:351-73.

5. Diamond SJ, Enestvedt BK, Jiang Z, Holub JL, Gupta M, Lieberman DA, i sur. Adenoma detection rate increases with each decade of life after 50 years of age. Gastrointest Endosc. 2011;74:13540.

6. Wilkins T, LeClair B, Smolkin M, Davies K, Thomas A, Taylor ML, i sur. Screening colonoscopies by primary care physicians: a meta-analysis. Ann Fam Med. 2009;7:56-62.

7. Irabor DO, Arowolo A, Afolabi AA. Colon and rectal cancer in Ibadan, Nigeria: An update. Colorectal Dis. 2010;12:43-9.

8. Mitrofanov IM, Nikolaev IuA, Dolgova NA, Pospelova TI. [Regional features of present-day polymorbidity of internal diseases]. Klin Med (Mosk). 2013;91:26-9.

9. Siegel R, Naishadham D, Jemal A. Cancer statistics, 2013. CA Cancer J Clin. 2013;63:11-30.

10. Australian Bureau of Statistics. National Health Survey: Summary of Results 2004-2005. Canberra: Commonwealth of Australia; 2006.

11. Wolff JL, Starfield B, Anderson G. Prevalence, Expenditures, and Complications of Multiple Chronic Conditions in the Elderly. Arch Intern Med. 2002;162:2269-76.

12. Jørgensen TL, Hallas J, Friis S, Herrstedt J. Comorbidity in elderly cancer patients in relation to overall and cancer-specific mortality. Br J Cancer. 2012;106:1353-60.

13. Robbins AS, Pavluck AL, Fedewa SA, Chen AY, Ward EM. Insurance status, comorbidity level, and survival among colorectal cancer patients age 18 to 64 years in the National Cancer Data Base from 2003 to 2005. J Clin Oncol. 2009;27:362733.

14. Aparicio T, Jouve JL, Teillet L, Gargot D, Subtil F, Le Brun-Ly V, i sur. Geriatric factors predict chemotherapy feasibility: ancillary results of FFCD 2001-02 phase III study in first-line chemotherapy for metastatic colorectal cancer in elderly patients. J Clin Oncol. 2013;31:1464-70.

15. Kim SE, Paik HY, Yoon H, Lee JE, Kim N, Sung MK. Sex-and gender-specific disparities in colorectal cancer risk. World J Gastroenterol. 2015;21:5167-75.

16. Vecchio R, Marchese S, Famoso S, La Corte F, Marletta S, Leanza G, i sur. Colorectal cancer in aged patients. Toward the routine treatment through laparoscopic surgical approach. G Chir. 2015;36:9-14.

17. Abbastabar H, Roustazadeh A, Alizadeh A, Hamidifard P, Valipour M, Valipour AA. Relationships of colorectal cancer with dietary factors and public health indicators: an ecological study. Asian Pac J Cancer Prev. 2015;16:3991-5.

18. Katsidzira L, Gangaidzo IT, Mapingure MP, Matenga JA. Retrospective study of colorectal cancer in Zimbabwe: colonoscopic and clinical correlates. World J Gastroenterol. 2015;21:2374-80.

19. Elzouki AN, Habel S, Alsoaeiti S, Abosedra A, Khan F. Epidemiology and clinical findings of colorectal carcinoma in two tertiary care hospitals in Benghazi, Libya. Avicenna J Med. 2014;4:94-8.

20. Hamilton W, Lancashire R, Sharp D, Peters TJ, Cheng KK, Marshall T. The importance of anaemia in diagnosing colorectal cancer: a case-control study using electronic primary carerecords. Br J Cancer. 2008;98:323-7.

21.Sideris M, Adams K, Moorhead J, Diaz-Cano S, Bjarnason I, Papagrigoriadis S. BRAF V600E mutation in colorectal cancer is associated with 
right-sided tumours and iron deficiency anaemia. Anticancer Res. 2015;35:2345-50.

22. Jones-McLean E, Hu J, Greene-Finestone LS, de Groh M. A DASH dietary pattern and the risk of colorectal cancer in Canadian adults. Health Promot Chronic Dis Prev Can. 2015;35:12-20.

23. Ahmadi A, Mobasheri M, Hashemi-Nazari SS, Baradaran A, Choobini ZM. Prevalence of hypertension and type 2 diabetes mellitus in patients with colorectal cancer and their median survival time: A cohort study. J Res Med Sci. 2014;19:850-4.

24. Liu R, Hu L, Li G, Zhao L, Li S, Zhang X, i sur. [Clinicopathological characteristics of colorectal cancer complicated with type 2 diabetes mellitus: analysis of clinicopathological data from 3,202 colorectal cancer patients]. Zhonghua Zhong Liu Za Zhi. 2014;36:74-7.
25.Huang CW, Sun LC, Shih YL, Tsai HL, Chen CW, Yeh YS, i sur. The impact on clinical outcome of high prevalence of diabetes mellitus in Taiwanese patients with colorectal cancer. World J Surg Oncol. 2012;10:76.

26. Thomopoulos C, Parati G, Zanchetti A. Effects of blood pressure lowering on outcome incidence in hypertension: 4 . Effects of various classes of antihypertensive drugs-overview and meta-analyses. J Hypertens. 2015;33:195-211.

27. Channanath AM, Farran B, Behbehani K, Thanaraj TA. Impact of hypertension on the association of BMI with risk and age at onset of type 2 diabetes mellitus: age-and gender-mediated modifications. PLoS One. 2014;9:e95308. 


\title{
FREQUENCY OF COMORBID DISEASES IN PATIENTS WITH COLORECTAL ADENOCARCINOMA
}

\author{
Pejana Rastovići, ${ }^{1,2}$ Snježana Šekerija ${ }^{1}$, Marko Kordić ${ }^{1}$, Anđela Azinović ${ }^{1}$, Zdrinko Brekalo ${ }^{1,2}$ \\ ${ }^{1}$ Clinic for Surgery, University Clinical Hospital Mostar, 88000 Mostar, Bosnia and Herzegovina \\ ${ }^{2}$ Faculty of Medicine, University of Mostar, 88000 Mostar, Bosnia and Herzegovina
}

\begin{abstract}
INTRODUCTION: Colorectal adenocarcinoma is one of the leading causes of morbidity and mortality worldwide. It is the most common in the elderly that are known to have a general increase in morbidity often in the form of chronic diseases associated to defined groups. Comorbid diseases in patients with colorectal adenocarcinoma significantly affect the course and outcome of treatment.

OBJECTIVE: To determine the incidence of the most common comorbid diseases in patients with colorectal adenocarcinoma hospitalized in UCH Mostar and compare them with the incidence of these diseases in the general population. The second objective was to determine whether there is a connection between comorbid diseases with seats of colorectal adenocarcinoma.

METHODS: In this retrospective study, a study group was consisted of 74 patients with colorectal adenocarcinoma who underwent surgery at the Clinic for Surgery of University Clinical Hospital Mostar, while the control group was consisted of 100 subjects from the general population. Input data were taken from the medical history or medical records. Comorbidities were considered nosological entities present and registered at the time of assessment before surgery.

RESULTS: The most common comorbid diseases in the study group were diabetes mellitus, hypertension and anemia. Patients with colorectal adenocarcinoma more frequently suffered from diabetes mellitus $(p=0.000)$, hypertension ( $p$ $=0.010)$ and microcytic anemia $(\mathrm{p}=0.01)$ compared to the control group. Patients with colorectal adenocarcinoma had significantly lower average of hemoglobin compared to controls $(\mathrm{p}=0.045)$. Statistically significant differences were not found in the frequency of comorbidity with respect to the seat of colorectal adenocarcinoma.

CONCLUSION: Patients with colorectal adenocarcinoma more often have diabetes mellitus, hypertension and microcytic anemia. There was no statistically significant difference in the incidence of these comorbidities regarding the seat of colorectal adenocarcinoma.
\end{abstract}

Keywords: colorectal cancer, comorbidities, diabetes mellitus, high blood pressure, anemia

Correspondence:

Pejana Rastović, MD

e-mail: pejana_rastovic@yahoo.com 